\title{
CLEAN AIR FOR INDIAN CITIES - CAUSES AND ALLEVIATION STRATEGIES
}

\begin{abstract}
Air pollution in cities across the world is rising at an alarming rate. This rise in pollution has an adverse effect on people's health leading to breathing difficulties, skin diseases and even cancer. The pollution in cities is mainly due to fossil fuel fired vehicles plying on the roads. Different polluting gases and particulate matter are discussed in the manuscript. Indian cities are no exception to this problem. With the general increase in population in the country, migration into cities has increased many folds. As a result, vehicular traffic on the roads has increased polluting the city atmosphere. This pollution has turned cities into heat islands. Two major cities of India, namely, Bengaluru and Delhi are considered in the manuscript for discussion. There are no simple ways of controlling this vehicular pollution and regulating the pollution. Strong policies have to be made and implemented. The way forward is pondered upon in the manuscript.
\end{abstract}

Keywords: Pollution, Health, Vehicular Emission, Electric Vehicles

\section{Sheela K. Ramasesha ${ }^{1}$ \\ ${ }^{1}$ Energy and Environment Research Programme, School of Natural Sciences and Engineering, National Institute of Advanced Studies, Indian Institute of Science Campus, Bengaluru 560012, India. sheela.ramasesha@gmail.com}

\section{Introduction}

Atmospheric pollution from transportation sector has been on the rise in the last few decades. Globally, in 2016 , about $7.87 \mathrm{Gt}$ of $\mathrm{CO}_{2}$ amounting to $24 \%$ of global $\mathrm{CO}_{2}$ emissions were from fuel combustion (IEA 2018). In the business as usual (BAU) scenario the passenger transport is predicted to increase three-fold between 2015 and 2050 (ITF 2019) and the emission from transport sector is expected to reach around 12 GtCO2eq/yr by 2050 (IPCC 2014). The increase in per capita transport demand in developing countries will be responsible for this increase in emissions.

\section{Pollution}

By convention air pollution is any substance humans emit into the atmosphere that has a damaging effect on the environment. These pollutants are both visible and invisible; and contribute to global warming. Since transportation sector makes a sizeable contribution to the air pollution, this article highlights the impacts of increased transportation in large cities in India and some suggestions to control this pollution are made here.

The impacts of transportation activity can be categorized into 3 classes, namely: direct, indirect and cumulative (Ports 2008). Direct impacts are the immediate effects of transport activities on the surroundings. Here the cause and effect relationships are usually well understood. For example, effect of noise and emission of carbon monoxide are known. The indirect impacts of transport activities on the environment are the secondary effects. It is not clear if these effects have higher consequence on environment and human health than direct impacts as the correlations are not well understood and are more difficult to establish. Most common example being the particulate matter that are emitted from the tailpipe of a vehicle because of the incomplete combustion in the engine, are associated with respiratory and cardiovascular problems. Then the third category is the cumulative impacts. This category encompasses the additive, multiplicative or synergistic consequences of transport activities that are the combinations of the direct and the indirect impacts on an ecosystem. Climate change is a cumulative impact of several natural and anthropogenic factors.

\section{Environmental Impact of buses}

Buses can be flexibly organized to transport citizens in big cities. Bus routes can be flexible enough to meet the needs of changing population and expansions in a city. They can provide connectivity to every corner of the city with appropriate interchanges. Since bus services are for mass transport of population, they are affordable, cost-effective and space efficient. Buses are efficient as far as fuel used per passenger-kilometer is concerned (IEA 2002). Furthermore, switching to buses would also mean an high saving in oil and reduction in pollution in addition to saving money. The road space occupied by a bus is about twice the space taken by a car but ferries many more passengers, could be about 10 times more.

There are economic and political angles associated with increasing the fleet of buses in big cities for transporting people. With increasing number of cars and other motorized smaller vehicles, demand for oil will grow steadily. With increasing transport demand in developing countries usage of buses makes more economic sense since a good bus system will 
substantially reduce oil usage in large cities. This will also put less pressure on the foreign exchange reserves of these countries by reducing the world oil demand.

Diesel, petrol and CNG are the most commonly used fuels for buses and all of them are produced from mineral oil that is commonly pumped out of an oil well, but the actual refining methods are different. Diesel is easier to refine than petrol and also contains higher levels of pollutants.

Petrol is a mix of alkanes and cycloalkanes with a chain length of between 5-8 carbon atoms. The alkanes from pentane $\left(\mathrm{C}_{5} \mathrm{H}_{12}\right)$ to octane $\left(\mathrm{C}_{8} \mathrm{H}_{18}\right)$ are refined into petrol. The boiling temperature is between $40^{\circ} \mathrm{C}$ and $200^{\circ} \mathrm{C}$. Diesel is made of alkanes containing 12 or more carbon atoms with a boiling temperature between $250^{\circ} \mathrm{C}$ and $350^{\circ} \mathrm{C}$.

The basic chemical reaction taking place inside combustion chamber in the Internal Combustion Engine (ICE) of a vehicle is,

Petrol/Diesel + Air Carbon Dioxide + Carbon Monoxide + Hydrocarbons + Nitrogen Oxides + Sulphur Dioxide + water + soot

The main pollutants coming out of a petroleum fuel fired vehicles are all toxic. For example:

Inhaled Carbon monoxide (CO) can block oxygen from vital organs like the brain, heart, and other vital organs. Carbon dioxide $\left(\mathrm{CO}_{2}\right)$ is a greenhouse gas that can trap heat in the atmosphere and cause global warming. Nitrogen oxides (NOx) are formed during combustion of fuels where temperature is above $\sim 1300$ $\mathrm{C}$ by oxidation of some of the nitrogen in air. These gases cause irritations in the lungs and weaken the body's immunity against respiratory infections. From global transportation, it is estimated that the direct emissions of $\mathrm{N}_{2} \mathrm{O}$ to be $0.142 \pm 0.065 \mathrm{Tg} \mathrm{N}_{2} \mathrm{O}-\mathrm{N} \mathrm{yr}^{-1}$ in 2010 (van der Zwaan et al. 2013). Sulfur dioxide $\left(\mathrm{SO}_{2}\right)$ is another pollutant generated by motor vehicles by burning sulfurcontaining fuels, especially diesel. $\mathrm{SO}_{2}$ is known to be responsible for acid rains and it is the largest health risk to young children and asthmatics. Particulate matter (PM) are particles of soot and metals which are responsible for the murky color to the smog. These fine particles are less than one-tenth the diameter of a human hair. These pose a serious threat to human health, as they can penetrate deep into lungs. PM of size $<0.1$ micron pass through the lungs into the blood stream and can settle in other organs. Diesel exhaust is a major contributor to PM pollution.

Hydrocarbons (HC) are fragments of fuel molecules which are partially burned. These molecules, in presence of sunlight, react with nitrogen oxides to form ozone at ground level, which is a primary ingredient in smog. In upper atmosphere ozone is beneficial but at ground level this gas is responsible for irritations of the respiratory system and reduces the lung capacity.

Hazardous air pollutants (toxics) which include Benzene, acetaldehyde, and 1,3-butadiene - are known to be carcinogenic. These chemical compounds are linked to cancer, birth defects and other serious illnesses.

The amount of $\mathrm{CO}_{2}$ emitted by burning petrol is $2.31 \mathrm{~kg} /$ litre whereas it is $2.68 \mathrm{~kg} /$ litre from a diesel engine. The energy content per litre in diesel is higher than petrol and diesel vehicles are more efficient to run than petrol engines because they are more efficient. Diesel does not contain any lead. However, when compared to petrol vehicles with catalytic converters, diesel vehicles have higher emissions of NOx and particulate matter.

Compressed natural gas is another fuel that is used to run buses. Natural gas consists of about $90 \%$ methane, with small amounts of higher alkanes. Methane is lighter than air, combusts almost completely giving out carbon dioxide and water as byproducts. There are issues like methane leak and emission of unburnt methane into the atmosphere.

A diesel bus engine emits 14, 5.5, 3.2, and 1.8 times higher $\mathrm{HC}, \mathrm{SO}_{2}, \mathrm{PM}$ and $\mathrm{NOx}$ emissions, respectively, when compared with the CNG bus. With longer the carbon chain, the probability of finding other elements like sulphur and nitrogen attached to it are higher. However, a CNG bus engine emits 20 times higher $\mathrm{CO}$ than diesel/petrol buses (Yasar et al. 2013). Also, because of longer carbon chains, diesel contains more energy per unit volume compared to CNG. Higher energy and better combustion efficiency would mean that diesel delivers greater power and ensures better mileage. If energy content, in other words, energy density is compared diesel scores the highest with 1.1 times that of petrol while CNG is $<40 \%$ of petrol (EIA 2013).

Though methane contributes little to the formation of low-level ozone it plays a major role in global warming. Though the life of methane in the atmosphere is only 12 years, it has a greater effect on climate. Based on the study of Shoemaker et al. short-term radiative forcing has an effect on the rate at which climate change occurs (Shoemaker et al. 2013). This study suggests that methane emissions, converted to carbon dioxide equivalents, have global warming potential (GWP) numbers of 28 for a 100 year time horizon but an alarming 84 for a 20 year time horizon (Myhre et al. 2013). As per the GREET model (Greenhouse gases, 
Regulated Emissions and Energy use in Transportation) developed by Argonne National Lab, under a 100-year GWP time horizon, natural gas emits 4 to 5 percent lower levels of GHG emissions than diesel throughout the fuel life cycle. But under a 20-year time horizon, 19 to 24 percent higher levels of GHG emissions than diesel. On a distance-specific metric (grams of $\mathrm{CO}_{2}$ eq per mile) that takes into account the differences in fuel efficiency, with an assumption that a 10 percent efficiency gap exists between natural gas and diesel engines, the natural gas emits $6 \%$ higher GHG than diesel under a 100 -year time horizon and under a 20-year time horizon, > 30\% GHG emissions than diesel (Delgado and Muncrief 2015). Actually, in India's capital city Delhi, most buses in the fleet of 5,500 utilize $\mathrm{CNG}$ for traction. A study concluded that, introduction of $\mathrm{CNG}$ buses did not change the pollution level. The study was conducted for 7 years from 2002 - 2009 (Saxena et al. 2012). Another drawback of CNG buses is that there is a drop in mileage with time. The study in Delhi, showed that within a span of six years, the mileage of buses had fallen from 2.88 to $2.63 \mathrm{~km}$ per $\mathrm{kg}$ of CNG. This is attributed mainly to newer buses having more powerful engines and growing traffic congestion leading to frequent startstop movement. This trend is consistent with what has been noted with diesel buses in other cities as well (Roychowdhury 2017).

\section{Possible solutions to reduce pollution in cities}

The number of vehicles in Bengaluru has increased from about 3.49 million in 2010 to 8.05 million in 2019 (Karnataka Transport 2019). Associated with this trend is the increase in pollution level. Bengaluru city, currently, has 16 pollution monitoring stations over its $709 \mathrm{Sq}$. $\mathrm{km}$ area. In 14 locations the measured PM10 was higher than the National Air Quality Standard limit of 60 micrograms $/ \mathrm{m}^{3}$. The annual average of PM level at the city center has increased from $72 \mathrm{micrograms} / \mathrm{m}^{3}$ in 2010 to 100.6 micrograms $/ \mathrm{m}^{3}$ in 2019. PM2.5 or PM10 were specifically not monitored in 2010. The value corresponds to suspended particulate matter whereas in 2019 it is specifically PM2.5. NOx, which is associated with vehicular traffic, increased from 72.6 micrograms $/ \mathrm{m}^{3}$ in 2010 to $111.8 \mathrm{micrograms} / \mathrm{m}^{3}$ (KSPCB 2011, CPCB 2010).

All petroleum-based fuels, namely, natural gas, diesel and petrol used for traction of buses pollute the surrounding atmosphere leading to smog that hangs over cities. Especially, due to temperature inversion in winters this effect is more severe. Winters are also notorious all over world for the flu and other respiratory illnesses because of pollution.
Thus, the only sensible option that exists to control emissions is to reduce the number of fossil fuel burning vehicles on city roads. Since buses can provide the last mile connectivity in cities and can be used for mass transportation of people, it makes sense to increase the number of buses to control pollution. For example, public transport in cities in Europe carried approximately 200 million people every day that was equivalent to about $21 \%$ of total mobility (IAPTU 2011). However, using fossil fuel burning buses will not help in reducing the pollution levels and replacing the current fleet of buses with electric buses is the only way forward to combat emissions in the atmosphere. With electric buses, though there are no direct emissions from the tailpipes, the electricity consumed for charging the batteries indirectly contributes to emissions. The amount of $\mathrm{CO}_{2}$ generated per $\mathrm{kWh}$ of electricity utilized is in the range $0.87-0.96 \mathrm{~kg}$ (CEA 2018). A detailed study on an electric bus, which was run on a trial basis, was conducted in Bangalore (Adheesh et al. 2016). The electric bus consumed 274 $\mathrm{kWh}$, for recharging the battery to travel a distance of $170 \mathrm{~km}$. According the Ministry of Power, Government of India (Power Ministry 2019), about $58 \%$ of the grid power in the country is generated from Coal fired thermal plants and $\sim 8 \%$ from Gas and oil sources. Taking these numbers into account and considering an average of $0.92 \mathrm{~kg} \mathrm{CO}$ per $\mathrm{kWh}$ for fossil fuels, there is an emission of $167 \mathrm{~kg}$ of $\mathrm{CO}_{2}$, that is less than the emission coming from a diesel run bus to travel the same distance, which is $\sim 212 \mathrm{~kg}$. So, annually over 25 tonnes of $\mathrm{CO}_{2}$ emissions can be saved by replacing even a single diesel bus by an electric bus. By deploying solar panels or other renewable sources for electricity generation at the battery charging stations of the electric buses, this emission can also be prevented. Here other kinds of pollutants that come out of diesel and coal burning, like the Water vapor, NOx and $\mathrm{SOx}$ are not accounted for.

There is an economic consideration that needs to be addressed. A diesel bus or a CNG bus costs around ₹ 8.5 million whereas an electric bus, that needs to be imported, costs around ₹ 20 -30 million. This is the upfront cost difference between the two types of buses. However, if electric buses are manufactured in the country, the unit cost would drop quite substantially. Many Indian companies like Ashok Leyland Limited, JBM Auto Limited, Deccan Auto Limited and Goldstone Infratech Ltd are entering into tie-up with industries around the world to start manufacturing electric buses (UITP India 2016). This will be a big boost to the implementation of these buses in the country. Currently, the operational cost of the electric bus was found to be ₹ 17.25 per km in Delhi. In contrast, a CNG AC bus costs ₹ 18.54 per $\mathrm{km}$. On average, the electric bus ran $250 \mathrm{~km}$ 
on a single charge. It consumed $27,368 \mathrm{kWh}$ electricity in the four-month period to cover a distance of 16,915 $\mathrm{km}$. With the price of CNG in Delhi is about ₹ 35.6 per $\mathrm{kg}$. A CNG bus gives a mileage of $1.95 \mathrm{~km}$ per $\mathrm{kg}$ and also requires higher maintenance (TOI 2016).

The electric buses in both the locations, namely, Bangalore and Delhi, did not breakdown during the trial period, largely because there's no engine or transmission system. In the long run, only the battery needs maintenance. Essentially, electric buses score on two fronts, Zero emission and lower manpower costs because of low maintenance.

The basic issues with the present scenario of public transport in big cities in India can be summarized as:

a) Number of buses to every one million population is small. For example, Delhi Transport along with the subsidiaries operates about 5500 buses with a population of 19 million whereas Bangalore with a population of over 12 million has a little over 6500 public transport buses. Hence, people in big cities are forced to use private transportation consequently increasing the number of vehicles on the road.

b) Because the public transport buses are fewer in number, they tend to get over crowded, slow moving and do not keep up the schedule. This again encourages people to use their own means of transportation.

c) The pollution from the tailpipes of buses and other motorized vehicles causes many health-related issues for people living in big cities, especially so when the buses are not well maintained.

In addition to the pollution aspects of vehicular transportation in the cities, there is the local weather aspect that should also be considered. The temperatures within the city can be 1-3 C higher than in the outskirts, for a city of 1 million population, due to trapped heat from traffic emissions and buildings (TERI. 2017). For Bangalore, with over 12 million population, this temperature difference could be higher than $5 \mathrm{C}$ and in New Delhi, it could be as high as 7-10 C.

Metro trains which run on electricity, have eased road traffic marginally in big cities like Delhi, Bangalore and Mumbai. The major problem with metros, however, is that, it is not viable to lay rail lines all across a crowded city. The roads are not broad enough to lay rail lines in most parts of the city. Drilling underground tunnels below the cities to have a wide network of metros is an expensive proposition and limitations in budgets will pose inhibitions to take up such large projects. While point to point connection on major routes is good with metros, the last mile connectivity will still depend on buses.
Thus, a combination of metro and electric buses appears to be a good solution to counter the pollution issues in big cities. The electric buses, as they cannot ply long distances on a single charge, can be engaged

in local service rather than for cutting across the city. For example, figure 1 shows the existing and planned routes of Metro in Bangalore. As can be seen between routes and between metro stations on a route, there are plenty of areas that cannot be serviced with the metro. Unless last mile connectivity is provided, citizens cannot be motivated to travel by metro. In many countries around the world, using public transport for an individual is a part of the daily routine since long and even if people have to walk a couple of kilometers, they do not mind the walk as it has become a habit. In Indian cities, public transport has been in such a bad shape all these years, to get people out of their private cars into public transport requires a big mindset change. It is easily said than done.

\section{Policies to control pollution in cities}

In order to improve the air quality and reduce pollution from vehicular transportation in Indian cities some major policies have to be implemented by the government and local civic bodies of these cities,

- First and foremost, requirement for Bangalore and other big cities in the country is to have a wide network of metro trains. As they run on electricity, the pollution in cities is reduced considerably. Of course, electricity generation sites will be polluting, if the electricity is generated from coal fired thermal plants which are generally located far from cities. Using cleaner ways of generating electricity will bring down the pollution associated with power generation. 


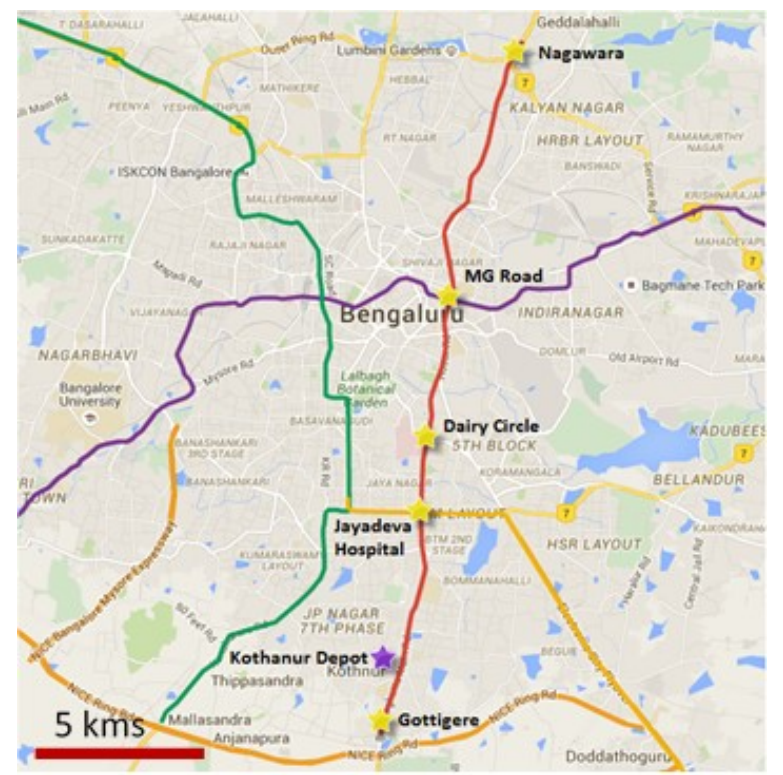

Fig 1. Existing and Planned Metro routes in Bangalore (BML 2016)

- There needs to be a well thought out network of public transport with electric buses that ferry people and act as feeders to metro stations from surrounding areas. These will provide the much needed last mile connectivity. Since the electric buses ply shorter distances on a single charge, they would be the best option for this purpose.

- In order to change the mindset of people about owning a car, private car ownership must be made difficult and discouraged.

- Private car usage, according to a study, is only $5 \%$ of the time and the other $95 \%$ of the time cars are parked (Fortune 2016). Each car occupies about $150 \mathrm{~m}^{2}$ of parking space. In a city like Bangalore, due to lack of parking facilities inside the properties, cars are parked on roads creating congestion and leading to increase in pollution of the local atmosphere. This also impacts the available space for walking and cycling. Heavy parking fees need to be levied for parking on roads.

- Encourage shared transport to and from metro stations. The regulatory measures must ensure that cab aggregators get a fair deal for providing good service. Digitized economy provides safety for the cab aggregators by not having to deal with cash. This will ease the traffic mayhem created on the roads by thousands of private cars.

Implementing these measures can control pollution in big cities in the country. The citizens can breathe easy and healthier air. This will also bring down enormously air borne diseases among the vulnerable population of the cities. In addition, if local climate conditions have to be maintained and cut down on the air-conditioner usage, it is imperative that the government makes policies based on above recommendations and implements them.

\section{References}

Adheesh SR, M. Shravanth Vasisht and Sheela K. Ramasesha, 2016 Air-pollution and economics: diesel bus versus electric bus, Current Science, 110(5), (2016), p $858-862$.

BML 2016, http://themetrorailguy.com/wpcontent/uploads/2016/05/BMLine4Map.png, Retrieved on July 4, 2020.

CEA 2018, Central Electrical Authority, User Guide. CO2 Baseline Database for the Indian Power Sector, 2018; http://cea.nic.in/reports/others/thermal/tpece/cdm_co2/use r_guide_ver13.pdf, Retrieved on Jan 7, 2020.

CPCB 2010, https://cpcb.nic.in/statistical-data/

Delgado and Muncrief 2015 - ICCT whitepaper : Assessment Of Heavy-Duty Natural Gas Vehicle Emissions: Implications And Policy Recommendations, O. Delgado, R. Muncrief, May 2015.

EIA 2013, https:/www.eia.gov/todayinenergy/detail.php?id=9991 \#, Retrieved on July 4, 2020.

Fortune 2016, http://fortune.com/2016/03/13/cars-parked-95percent-of-time/, Retrieved on Jan 7, 2020

IAPTU 2011, International Association of Public Transport Union, Internationale des Transports Publics position paper, Towards low/zero-carbon urban mobility in Europe. Focus, 2011, 1-6; http://www.uitp.org/ sites/default/files/cck-focus-papersfiles/FPNov2011.pdf

IEA Publication, "Bus Systems for The Future - Achieving Sustainable Transport Worldwide", 2002

IEA, 2018, IEA CO2 Emissions from Fuel Combustion, OECD/IEA, Paris 2018.

IPCC, 2014: Climate Change 2014: Synthesis Report. Contribution of Working Groups I, II and III to the Fifth Assessment Report of the Intergovernmental Panel on Climate Change [Core Writing Team, R.K. Pachauri and L.A. Meyer (eds.)]. IPCC, Geneva, Switzerland, 151 pp.

ITF (2019), ITF Transport Outlook 2019, OECD Publishing, Paris, https://doi.org/10.1787/transp_outlook-en-2019-en, Retrieved on Jan 7, 2020.

Karnataka Transport https://transport.karnataka.gov.in/index.php/info4/Vehicles+Statistics/en

KSPCB 2011, Karnataka State Pollution Control Board, Annual report 2010-11.

Myhre, G., shindell, D., Bréon, F.-M., collins, W., Fuglestvedt, J., huang, J., ... Zhang, h. (2013). Anthropogenic and natural radiative forcing. in Climate change 2013: The physical science basis. Contribution of Working Group I to the Fifth Assessment Report of the Intergovernmental Panel on Climate Change (pp. 659684). cambridge and new York: cambridge university Press. retrieved from http://www.climatechange2013.org/images/report/Wg1 ar5 _chapter08_Final.pdf 
Ports JF, Jr.2008, National Highway Traffic Safety Administration, DEIS 2008

Power

Ministry

http://powermin.nic.in/en/content/overview, retrieved on Jan 7, 2020

Roychowdhury A., Gaurav Dubey and Anu Soman 2017, Waiting for a bus: Strategies to improve Delhi's bus system, Centre for Science and Environment, New Delhi

Saxena P., R. Bhardwaj and C. Ghosh, 2012, Status of Air Pollutants after Implementation of CNG in Delhi, Curr. World Environ., Vol. 7(1), (2012), p. 109-115.

Shoemaker, J. K., Schrag, D. P., Molina, M. J., and Ramanathan, V. (2013). What role for short-lived climate pollutants in mitigation policy? Science, 342(6164), (2013), p. 1323-1324.

T E R I. 2017 Final Report on Urban Planning Characteristics to Mitigate Climate Change in Context of Urban Heat Island Effect Bangalore : The Energy and Resources Institute. 82 pp. [Project Report No. 2016BG03]

TOI 2016, https://timesofindia.indiatimes.com/city/delhi/Trial-asuccess-DTC-eyes-longer-electric-

run/articleshow/53746447.cms, retrieved on Jan 7, 2020

UITP India 2016: http://www.india.uitp.org/articles/electricbus-market-in-india, retrieved on Jan 7, 2020

van der Zwaan B., I. Keppo and F. Johnsson, Energy Policy 61, October 2013, Pages 562-573

Yasar A., R. Haider, A.B. Tabinda, F. Kausar and M. Khan, (2013), A Comparison of Engine Emissions from Heavy, Medium, and Light Vehicles for CNG, Diesel, and Gasoline Fuels, Pol. J. Environ. Stud. Vol. 22, No. 4 (2013), p. 1277-1281 